\title{
Readiness towards E-learning amongst Telecenter Users
}

\author{
Yuhanis Yusof, Chek Derashid, Mazri Yaakob, Rohani Husin \\ International Telecommunication Union-Universiti Utara Malaysia \\ Asia Pacific Center of Excellence for Rural ICT Development, Malaysia
}

\begin{abstract}
This paper investigates students' readiness and attitudes towards E-learning facility. Respondents involved were users of telecenters that are located in rural areas of Peninsular Malaysia. Results have shown that the students have positive attitude towards the usefulness of e-learning but ICT infrastructure may limit their interest. Based on such findings, this paper also provides insight of an intelligent user-centric e-learning portal that presents users with dynamic learning content. Each user is to be presented with content that suits their interest and capabilities. Hence, it may attract the user to maximize the usage of the learning portal.
\end{abstract}

Keywords: e-learning, bridging digital divide, telecenter, user-centric model.

\section{Introduction}

The rapid pace of technological and economic developments has placed greater demands on education systems. The crucial need for students is to focus on the importance of lifelong learning, that is, to continuously upgrade their knowledge and skills, to think critically and to inspire creativity and innovation so as to adapt to global change [1]. Recently, a new paradigm of teaching and learning process, e-learning, has emerged as a result of the rapid diffusion of ICT. E-learning is a type of teaching and learning that one can be obtained by the means of online technology.

Instead of going to school and attend a regular class, e-learning is done in the comfort of one own home or an identified location. It is also referred to as online learning or virtual learning that is currently undertaken utilizing the ICT technology. This includes the delivery of content via Internet, audio- and videotape, satellite broadcast, interactive TV, and CD-ROM [2]. However, in order to benefit from these advantages, students will need to be able to adopt a new attitude towards e-learning models [3]. Therefore, investigating the readiness and attitude towards these models is important for their success. The research literature on e-learning has grown significantly. Nevertheless, existing work focuses on the higher level education that includes university students $[4,5]$ and people who are currently working [6]. The main purpose of this paper is to analyze the readiness of telecenter users (in particular primary school students) in adopting elearning as learning methods.

The remainder of the paper is organized as follows: section 2 covers the literature review from recent studies that have been covered in the context of e-learning implementation and adoption; this is followed by the implementation of telecenters in Malaysia. Section 4 looks at the methodology adapted for this research while Section 5 presents the result. The overall discussion of the potential of the e-learning as well as the set of recommendations to introduce e-learning in supporting traditional learning methods is included in Section 6. The conclusion is given at the end of the paper detailing the lessons learnt from the research.

\section{E-Learning}

The importance of e-learning is widely recognized as a mean to enhance accessibility and quality of teaching learning process [2]. E-learning is viewed as a tool for providing opportunities for marginalized and disadvantaged students or who are seeking learning support. A wider range of students can be reached anytime and anywhere provided that the Internet connection is available. Besides, significant literature indicated that online learning, in particular, Virtual Classroom (VCR) supported critical thinking skills [7], problem-solving [8], communication and interaction [5] and flexibility in time management [9]

While it has many benefits, online learning has many challenges. There is a great concern among researchers regarding the issue of the digital divide. As is well known, a significant segment of individuals still does not have access to the Internet or does not have the required IT skills. Although the rapid development of ICT provides easier and more affordable connectivity to the Internet, thereby narrowing the digital divide, equitable access will continue to be a major concern to governments worldwide, even in developed countries. Common problems also indicated by previous studies regarding the new skills required that will enable learners and teachers to use and benefit from e-learning models [10]. Presumably, the more experience in using the computer and Internet, the more likely students and teachers will be inclined to accept and use e-learning style.

Parents have also concerns about children's social development [11]. In an online environment, students may feel isolated. Although online courses provide various opportunities for learners to interact with each other and 
with their tutors such as live chats, discussion boards, group project which reduce feelings of isolation [5] yet there is a need to develop and promote e-learning process by enabling learners to become self-motivated, selfreliant and self-managing. Since e-learning is about individuals and about using technology systems to support constructive social interactions, it may work best when it is combined with some face-to-face classroom experience [11].

In general, technologies present opportunities [12]. The real challenge lies in not only ensuring that certain preconditions are met for e-learning, such as access to ICT tools, networks and literacy, but also that of how to change the perception learners towards e-learning. For the success of an e-learning implementation, there is a need to acknowledge the importance of assessing readiness of organizations, teachers and learners to adapt this learning style [13]. An e-learning readiness evaluation can help an organization to identify potential aspects that are necessary to ensure that the design of e-learning strategies tailored to meet learners' needs and how teachers and learners come to accept and use an e-learning style as well [13].

There have been many works in addressing the issues of readiness to e-learning. In [6], the researchers have introduced a self-assessment instrument of an e-learning technology. They measure an individual's perceived readiness to engage in e-learning via an instrument consisting of 10 categories. The work done by [13] proposes the use of interactive Web-based application prototype called Alaws Educational Network. The platform has received a positive feedback from the high secondary students. In addition, it is also reported that there are many challenges being faced in implementing a virtual classroom in Palestine including digital divide, technical limitations of the network, lack of e-learning technologies skills, lack of motivation and language. A similar conclusion can also be seen in $[4,14]$ where the researcher assess the level of readiness of school students in utilizing e-learning as to enhance access, equity and quality in education. It is learned that ICT infrastructure such as digital equipments and internet connectivity need to be ready in order to ensure the success of an e-learning. Furthermore, sufficient training programs son how to integrate ICT in education should also be conducted to teachers and the relevant officers.

On the other hand, [15] examine the readiness of adopting e-learning amongst Hong Kong's primary and secondary school teachers. They found that the teachers are not yet fully prepared to use e- learning technologies - with differences in readiness perceived between male and female; and secondary and primary school teachers; as well as between teachers from different secondary school. Supporting such findings is the work done in University of Tabuk [16]. The study findings revealed that $62.9 \%$ of the faculty members' overall responses to e-learning perception survey were ranging from negative to 'uncertain'. There was a significant difference among faculty members' e-learning perception related to their major and experience. Novice faculty members showed more positive e-learning perception than experienced ones in e-learning readiness. Faculty members of Computer Science, Engineering, Education, and Arabic were a little bite positive than other faculty members.

\section{Telecenters In Malaysia}

Information and communication technologies (ICTs) have been widely used as solutions to improve organizations. ICT had empowered users in organization to improve productivity through increased efficiency to collect, process, store, and disseminate data and information to enable managers to plan, operate, monitor and make better decisions. Users are able to gain knowledge and improve competency as well as worked together from anywhere, any time through the connectivity to the internet. The Malaysian government has implemented many ICT initiatives to help bridge the digital divide since 1998. One of the initiatives is to provide a public place where people can access computers, the Internet and other digital technologies that enable them to gather information, create, learn and communicate with others. The ICT community centre, also known as a telecentre is built in selected areas to provide access to ICTs for the target groups who cannot afford to own their own PC especially to the rural and underserved communities [17]. TCs do not just provide affordable or free ICT support and services, but is an important affordable capacity building centres for the underserved communities.

There are several other models of TCs like the Community Broadband Centres (CBCs) and Community Broadband Libraries (CBLs), implemented by Malaysian Communication and Multimedia Commission (SKMM), that are also very successful. The model of the CBCs has incorporated the characteristics of the PIDs and Kedai.com models (another TC initiative implemented in 2003 placed in selected shops by SKMM) that have evolved since their inception. The vibrant knowledge sharing community in the Economic Planning Unit of the Prime Minister's Department (EPU), MEWC, SKMM and other agencies together with individuals had enabled the TC implementation knowledge obtained be captured in the design of the CBCs and future TCs.

In the case of CBCs, local governments and community leaders were drawn in to provide commitment to the existing partnerships between the government and private sectors (PPP) to help implement the CBCs and CBL. The partnerships were formed between SKMM, and Telecom Malaysia Bhd. The funding of the projects comes 
partly from the Universal Service Provision (USP) funds set up by the government to fund the ICT development for underserved communities in the country.

There are other TC initiatives such as the Medan Infodesa (MID) implemented by the Ministry of Rural and Regional Development (MRRD) to bridge the digital divide. MIDs had helped trained many people from all walk of life. Private sector participation, like Maxis Berhad, a telecommunication company that had implemented many projects such as Maxis Cyberkids camp, Community carnival, and Maxis Cyberlab to provide ICT awareness and capacity building training programmes for various citizens.

\section{Methodology}

The aim of this work is to investigate the potential of e-learning to support the learning process for students in Malaysia. In particular, we are focusing on primary students (aged 10 to 12) living in the rural areas. The respondents were obtained from six (6) TCs in northern areas of Peninsular Malaysia : two (2) TCs in Perlis (PID Simpang Empat and MID Kok Kelang) and four (4) in Kedah state (PID Yan, MID Lubok Sireh, MID Kg Bukit and MID Paya Semambu).

As community of the identified areas may not have the same ICT opportunity and exposure, the need to analyse student readiness and awareness on e-learning may contribute to a better education policy, e-learning model and marketing strategies. The work presented in this paper addresses the following questions: What are the perceptions of students regarding the usefulness of e-learning? To what extend do students ready to adapt learning via online tools, and what are the challenges that need to be overcome in order to ensure that the identified students would benefit from an e-learning approach. The questionnaire consists of two parts; Section A is on the demographic information of the respondent while Section B includes questions that will indicate the respondents understanding on e-learning.

\section{Results}

This section presents the results from the undertaken survey while its discussion is presented in the following section. The result presented in this section is gathered from a total of 78 students. Eighty percent of the respondents are in the range of 10 to 12 years old while the rest are below than 10 but are older than 6 years. A detail of the distribution is illustrated in Figure 1. Out of the 78 students, 22 are male while 78 are female.

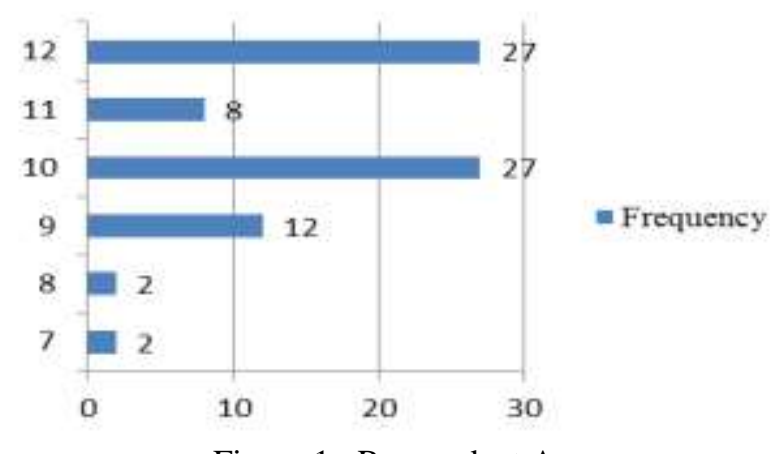

Figure 1 : Respondent Age

In Figure 2, the self-assessment instrument also reveals that approximately $39 \%$ of the students admit that they are computer novice users. Out of the 78 students, only 8 students declare themselves as being advanced.

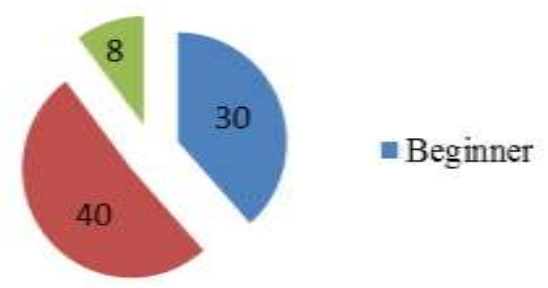

Figure 2 : Level of Computer Users

As community of the rural areas may has limited financial, the setting-up of telecenters that provides ICT infrastructure is seen to benefit this group of community. Through this study, it is also learned that only a small 
amount of students utilizing the center efficiently (refer to Figure 3). Only 9 students visit the center more than 9 times per week while 39 visited the center at most of 3 times in a week.

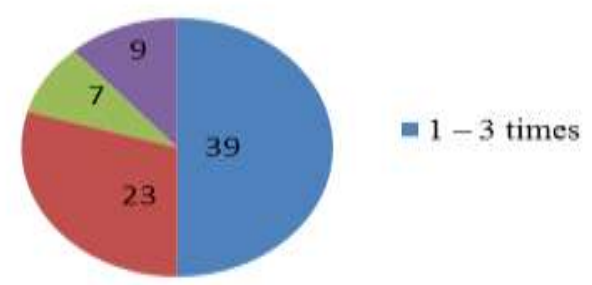

Figure 3: Frequency of Visiting Telecenter

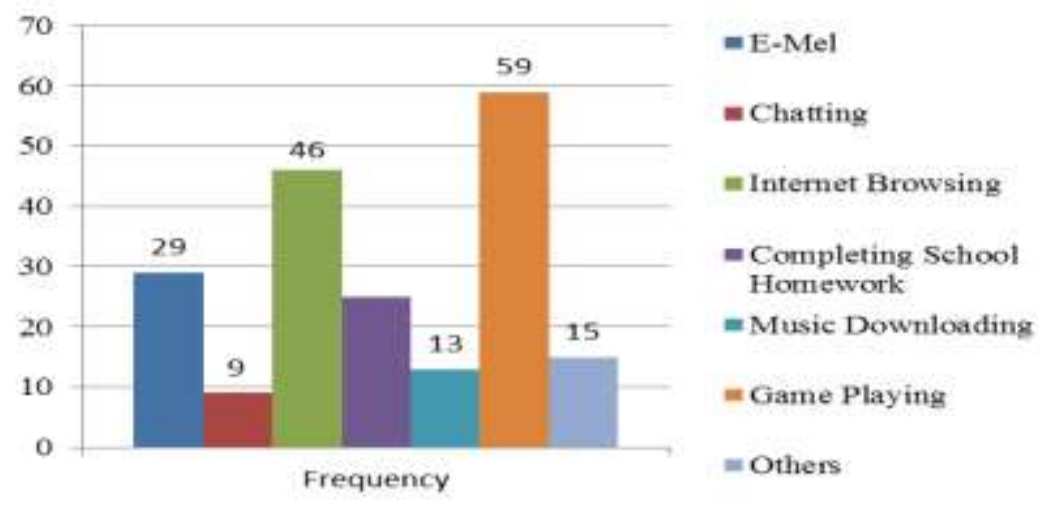

Figure 4 : Activities while Online

While visiting the center, there are 6 main activities being carried out by these students; emailing, chatting, internet browsing, completing school homework, music downloading and game playing. Most of the students is reported to spend their time in playing online games. Among the popular games are the "Angry Bird", "FIFA", "Needs for Speed" and "Counter Strike". The second popular activity is internet surfing and this is followed by emailing. Figure 4 shows details of the activities.

Out of the 78 respondents, only 4 of them have the experience of using online courses. The four students claimed that they have followed either the 'SKOR A' or 'tutor.com.my' in supporting their education. It is learned that 55 students are interested to join online courses while 18 of them rejected on utilizing online learning to support their education. In Figure 5, it is illustrated the preferred subjects for online learning. The presented chart shows that most of the respondents requires online learning for the English subject while only $2 \%$ is seeking for Arabic online support. Such a finding support existing claim that students of rural areas are lacking of English skills [18].

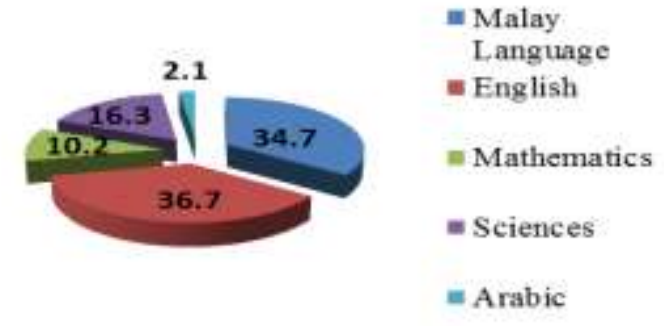

Figure 5: Preferred Subjects for Online Learning

As for the basic infrastructure such as having a computer at home, 54\% of the students do not have such facility. Only $46 \%$ of them admitted that their parents or guardian owned a PC or laptop. For the ones with computer, a total of $41 \%$ are not connected to the internet. Reasons given of not having the internet connectivity are mainly because of the initial and maintenance cost. 
In this study, respondents were also asked to self-evaluate their understanding on e-learning. This includes statements as depicted in Table 1. Students perception on e-learning was measured using the Likert scale where $1=$ strongly not agree and $5=$ strongly agree. The average result (refer to the 'Mean' and 'Std Deviation' column in Table 1) obtained indicated that all of the respondents understood what is e-learning.

Table $1:$ Statements on E-Learning

\begin{tabular}{|l|l|c|c|}
\hline No. & \multicolumn{1}{|c|}{ Item } & Mean & $\begin{array}{c}\text { Std. } \\
\text { Dev. }\end{array}$ \\
\hline 1 & A new way of learning for students & 4.0897 & .74181 \\
\hline 2 & An ICT application & 3.8590 & .96328 \\
\hline 3 & $\begin{array}{l}\text { Requires additional commitment in } \\
\text { learning and teaching }\end{array}$ & 4.2051 & .76207 \\
\hline 4 & $\begin{array}{l}\text { A learning method that utilizes } \\
\text { computer and internet }\end{array}$ & 4.0128 & .88997 \\
\hline 5 & $\begin{array}{l}\text { Eased the learning process as } \\
\text { continous learning can be done } \\
\text { regardless of location and number of } \\
\text { students. }\end{array}$ & 3.9744 & .86751 \\
\hline
\end{tabular}

The respondents were further asked on their perception of e-learning. This is to investigate if these students are interested and motivated to undertake such learning process. Table 2 includes the relevant statements and its results. Data depicted in the table suggested that the students are interested in new learning technologies such as e-learning, nevertheless, they are lacking of relevant ICT training programmes. Hence, they do not have sufficient ICT knowledge and skills.

Table 2: Perceptions on E-Learning

\begin{tabular}{|l|l|c|c|}
\hline No. & \multicolumn{1}{|c|}{ Item } & Mean & Std. Dev. \\
\hline 1 & I like to try new approach in learning and this includes e-learning. & 4.2821 & .71890 \\
\hline 2 & I am interested in ICT. & 4.2179 & .80012 \\
\hline 3 & I don't want to be left behind in using new approaches of learning. & 4.1282 & .91678 \\
\hline 4 & I always follow recent learning technologies. & 3.6795 & .71157 \\
\hline 5 & I have depth knowledge and high skill in ICT and computing. & 3.3718 & .86953 \\
\hline 6 & I always undertake ICT courses and trainings. & 2.8462 & 1.34914 \\
\hline 7 & I belief every house should have internet connectivity. & 4.0385 & .84427 \\
\hline 8 & I am willing to spend time on learning and utilizing e-learning. & 3.8205 & .92222 \\
\hline 9 & I think online learning is more effective than offline learning. & 3.8718 & .84298 \\
\hline
\end{tabular}

\section{Discussion}

Based on the findings of the study, there are two main issues that need to be addressed. First, is the ICT infrastructure problem, where the involvement of public and private sector would contribute to a better education, specifically to the ones that are living in rural areas. Perhaps the cost of purchasing and connecting to the internet can be revised so that digital divide between communities from the rural and urban areas can be reduced. Furthermore, more creative and innovative ICT training programmes is required to be held for the rural students in order to ensure that they always motivated for life-long learning. It can be seen that, currently, even though there has been initiatives such as telecenter, nevertheless the children are not fully utilizing the center to increase their academic performance. This leads to the second issue of how to motivate the students in utilizing online courses to support their traditional learning (face-to-face) process. This paper proposes an intelligent user centric model to be adopted in an e-learning portal. Similar to the one presented in [19], an e-learning portal that is dynamic and presents users with the 'relevant' content is required. What is meant by 'relevant' is that students should be exposed to materials that suit his/her academic background. This means that a student of level A should have the materials of type 'difficult' and vice versa. In addition, the materials should also be presented according to students learning styles [20]. For example, students whom are categorized as 'visual learners' should be presented with material in a visual form while the 'audio learners' may have materials that include audio components.

In order to develop such intelligent model, various learning mechanism need to be incorporated in the model. Recent studies on evolutionary computing reveal that the utilization of nature-inspired algorithms such as Neural Network [21], Ant Colony [22] and Artificial Bee Colony [23] has demonstrated positive results. Hence, 
it is suggested that one of these techniques is included in the developing an e-learning portal. Information on students learning behaviour can be identified via these algorithms and this information is later combined with the family background before relevant learning materials is presented to a student.

\section{Conclusion}

This paper discusses the readiness of primary students living in rural areas of Peninsular Malaysia in undertaking e-learning. Based on the findings, it is learned that these children are willing and motivated to utilize ICT (in particular the e-learning portal) in their education. Nevertheless, relevant and sufficient ICT services, such as creative ICT training programmes that may provide different insight of ICT, are required to motivate the children to learn better. Hence, ICT initiatives such as telecenters can further be more utilized. Furthermore, it is best if ICT educational tools (such as e-learning portal) could be personalized so that the learning process can be tailored to the needs and specialty of the children.

\section{References}

[1] UNESCO, "Integrated ICT into Education: Lesson Learned," UNESCO Asia and Pacific Regional Bureau for Education, Bangkok, Thailand, Bangkok 92-9223-015-8, 2004.

[2] S. Zu, "E-Learning Importance and Design," in Distance Education and E-Learning White Papers, 2009.

[3] P. D. Johna and R. Sutherland, "Teaching and learning with ICT: new technology, new pedagogy?," Education, Communication \& Information, vol. 4, pp. 101-107, 2004.

[4] D. R. Paudyai, "E-Learning Experiences and Sustainability: A Piloting of Distance MSc. Thesis Spervision at ITC, The Netherlands," in International Archives of the Photogrammetry, Remote Sensing and Spatial Information Science, 2006, pp. 254-259.

[5] J. Gilbert, S. Morton, and J. Rowley, "e-Learning: The Student Experience," British Journal of Educational Technology, vol. 38, pp. 560-573, 2007.

[6] R. Watkins, D. Leigh, and D. Triner, "Assessing Readiness for E-Learning," Performance Improvement Quartely, vol. 17, pp. 66-79, 2004.

[7] C. Lesdon-Bandeira, "Using e-Learning to Promote Critical Thinking in Politics," Enhancing Learning and Teaching in the Social Sciences, vol. 1, pp. 1-14, April 2009.

[8] C. Stary and G. Weichhart, "An E-Learning Approach to Informed Problem Solving," International Journal on Knowledge Management \& E-Learning, vol. 4, pp. 195-216, 2012.

[9] G. Yoshiko, M. Takeshi, Y. Masanori, S. Yutaka, K. Hiroshi, and M. Hiroyuki, "Ingenious Attempts to Develop Self-Regulated Learning Strategies with e-Learning: Focusing on Time-Management Skill and Learning Habit," in World Conference on E-Learning in Corporate, Government, Healthcare, and Higher Education 2009 Vancouver, Canada: AACE, 2009.

[10] A. Andersson and A. Gronlund, "A Conceptual Framework for E-Learning in Developing Countries: A Critical Review of Research Challenges," The Electronic Journal on Information Systems in Developing Countries, vol. 38, pp. 1-16, 2009.

[11] C. Cavanaugh, "The effectiveness of interactive distance education technologies in K-12 learning: A meta-analysis," International Journal of Educational Telecommunications, vol. 7, pp. 73-88, 2001.

[12] M. O. Yusuf, "Information and Communication Technology and Education: Analysing the Nigerian National Policy for Information Technology " International Education Journal, vol. 6, pp. 316-321, 2005.

[13] K. Shraim and Z. Khlaif, "Students' Readiness Towards E-learning. A case study of Virtual Classrooms for Secondary Education in Palestine," in 3rd Annual Forum on e-Learning Excellence Bringing Global Quality to a Local Context, Dubai U.A.E, 2010.

[14] D. Karanja, "E-learning Readiness in Public Secondary Schools in Kenya: The Case of Nakuru Municipality," in School of Education. vol. Master: Kenyatta UNiversity, 2012.

[15] T. So and P. M. C. Swatman, "e-Learning Readiness of Hong Kong Teachers," in 5th IEEE International Conference on Advanced Learning Technologies, Hong Kong, 2005.

[16] A. Albalawi and M. Badawi, "Teachers' Perception of E-learning at the University of Tabuk," in World Conference on E-Learning in Corporate, Goverment, Healthcare, and Higher Education, Las Vegas, USA, 2008.

[17] B. Fillip and D. Foote, Making the Connection: Scaling Telecenters for Development. Washington: Information Technology Applications Center (ITAC) of the Academy for Education Development, 2007.

[18] P. Padmini and M. Anbukkani, "Challenges Encountered by Teachers in Rural Areas and Strategies to Triumph Over," Language in India, vol. 10, pp. 160-169, 2010.

[19] M. Kam, A. Agarwal, A. Kumar, S. Lal, A. Mathur, A. Tewari, and J. Canny, "Designing E-Learning Games for Rural Children in India: A Format for Balancing Learning with Fun," in Proceedings of the 7th ACM conference on Designing interactive systems, Cape Town, South Africa, 2008, pp. 58-67.

[20] A. P. Gilakjani and S. M. Ahmadi, "The Effect of Visual, Auditory, and Kinaesthetic Learning Styles on Language Teaching " in International Conference on Social Science and Humanity, Singapore, 2011, pp. 469-472.

[21] V. O. Oladokun, A. T. Adebanjo, and O.E. Charles-Owaba, "Predicting Students' Academic Performance using Artificial Neural Network: A Case Study of an Engineering Course," The Pacific Journal of Science and Technology, vol. 9, pp. 72-79, May-June 20082008.

[22] I. B. Junior and Z. Čičková, "Solving the Travelling Salesman Problem Using the Ant Colony Optimization," Management Information Systems, vol. 6, pp. 10-14, 2011.

[23] P. Y. Kumbhar and S. Krishnan, "Use of Artificial Bee Colony(ABC) Algorithm in Artificial Neural Network Synthesis," International Journal of Advanced Engineering Sciences and Technologies, vol. 11, pp. 162-171, 2011. 